\title{
IDENTIFIKASI JAMUR Candida sp DAN Aspergillus sp PADA SPUTUM LANSIA DI PANTI SOSIAL TRESNA WERDHA BUDI MULIA 1 CIPAYUNG JAKARTA TIMUR DENGAN METODE HVC PADA SUHU $40^{\circ}$ C DAN SUHU KAMAR
}

\author{
Rawina Winita ${ }^{1)}$, *Lenggo Geni' ${ }^{2}$, Vita Amalia ${ }^{2)}$ \\ ${ }^{1}$ Parasitologi Fakultas Kedokteran Universitas Indonesia' \\ ${ }^{2}$ Program Studi Analis Kesehatan, Fakultas Kesehatan, Universitas Mohammad Husni Thamrin \\ Correspondence author: Lenggo Geni, lenggogeni19@gmail.com, Jakarta, Indonesia
}

\begin{abstract}
ABSTRAK
Mikosis adalah infeksi jamur yang pertumbuhannya dipengaruhi oleh lingkungan dan kondisi fisiologis. Lansia pada panti jompo merupakan salah satu kelompok yang rentan terinfeksi jamur dikarenakan rendahnya sistem imun atau bahkan pengaruh dari kualitas lingkungan sekitarnya. penelitian ini untuk mengetahui jenis jamur pada sputum lansia yang mengalami batuk dan tidak batuk di Panti Sosial Tresna Werdha Budi Mulia 1 Cipayung Jakarta Timur dengan sampel 50 berupa sputum lansia yang mengalami batuk sebanyak 25 dan tidak mengalami batuk sebanyak 25 , pemeriksaan ini menggunakan metode $\mathrm{HCV}$ pada suhu $40^{\circ} \mathrm{C}$ dan suhu kamar. Dari hasil kepadatan jamur Aspergillus $s p$ dan beberapa jenis jamur lainnya lebih banyak didapatkan pada suhu kamar dibandingkan dengan suhu $40^{\circ} \mathrm{C}$ Sedangkan pada jamur Candida sp lebih banyak didapatkan pada suhu $40^{\circ} \mathrm{C}$ dibandingan dengan suhu kamar. Kepadatan jamur Candida $s p$ positif-1 lebih banyak didapatkan pada suhu $40^{\circ} \mathrm{C}(60 \%)$ dibandingkan pada suhu kamar yaitu 17 (50\%) sedangkan pada kepadatan Candida $s p$ positif-2 lebih banyak didapatkan pada suhu kamar yaitu 17 (50\%) dibandingkan dengan suhu $40^{\circ} \mathrm{C} 8$ (40\%). Jamur Aspergillus fumigatus pada suhu $40^{\circ} \mathrm{C}$ lebih banyak didapatrkan pada lansia yang tiak mengalami batuk dibandingkan dengan lansia yang mengalami batuk.Dapat disimpulkan bahwa lansia yang mengalami batuk maupun tidak batuk pada Panti Sosial Tresna Werdha Budi Mulia 1 kemungkinan terinfeksi oleh jamur pada sputumnya.
\end{abstract}

Kata kunci : Sputum, Batuk dan Tidak Batuk, Lansia, Aspergillus sp, Candida sp, Panti Sosial Tresna Werdha Budi Mulia 1 Cipayung Jakarta Timur.

\begin{abstract}
Mycosis is a fungal infection whose growth is influenced by environmental and physiological conditions. The elderly in nursing homes are one of the groups susceptible to being infected with fungi due to the low immune system or even the influence of the quality of the surrounding environment. this study to find out the type of fungus in elderly sputum who had a cough and did not cough at Tresna Werdha Budi Mulia Social Home 1 Cipayung East Jakarta with a sample of 50 elderly people who had coughed as much as 25 and did not cough as much as 25 , this examination used hov method at $40 \mathrm{OC}$ temperature and room temperature. From the density of aspergillus sp mushrooms and some other types of fungi are more obtained at room temperature compared to $40 \mathrm{oC}$ while in Candida sp mushrooms are more obtained at $40 \mathrm{oC}$ than in room temperature. Candida sp positive- 1 fungal density is more widely obtained at $40 \mathrm{oC}(60 \%)$ compared to room temperature of $17(50 \%)$ while at candida sp positive-2 density more is obtained at room temperature which is $17(50 \%)$ compared to a temperature of $40 \mathrm{oC} 8(40 \%)$. Aspergillus fumigatus fungus at $40 \mathrm{oC}$ is more likely to be found in elderly people who have a cough compared to the elderly who have coughed. It can be concluded that the elderly who have a cough or do not cough at Tresna Werdha Budi Mulia Social Center 1 are likely infected by the fungus in the sputum.
\end{abstract}

Key words: Sputum, Cough and No Cough, Elderly, Aspergillus sp, Candida sp, Tresna Werdha Budi Mulia 1 Social Home, Cipayung, East Jakarta.

Open Journal System (OJS): journal.thamrin.ac.id

http://journal.thamrin.ac.id/index.php/anakes/issue/view/35 


\section{PENDAHULUAN}

Mikosis adalah infeksi jamur yang pertumbuhannya dipengaruhi oleh lingkungan dan kondisi fisiologis. Inhalasi spora jamur atau pembentukan koloni jamur pada kulit dapat menyebabkan infeksi parsisten. Mikosis dapat terjadi pertama kali di kulit atau di paru-paru. (hasanah.U, 2017).

Kelompok jamur oportunistik hanya menginfeksi pejamu dengan gangguan pada sistem imun atau terdapat faktor predisposisi. Pada keadaan normal spora jamur oportunistik sulit menginvasi mukosa saluran nafas. Pada pasien dengan immunocompromissed, spora yang terinhalasi dan berkolonisasi akan menginvasi jaringan paru dan berkembang sehingga mengakibatkan kerusakan jaringan paru dan menimbulkan gejala klinis. Sistem pertahanan tubuh baik spesifik maupun nonspesifik tidak dapat berfungsi dengan baik pada individu yang mempunyai status imun buruk, seperti pemakaian kortikosteroid lama, diabetes melitus dan lanjut usia. (http://www.klikparu. com/2013/02/ jamurparu.html).

Gejala umum infeksi jamur paru sama dengan infeksi mikroba lainnya, antara lain batuk-batuk, batuk darah, banyak dahak, sesak, demam, nyeri dada dan bisa juga tanpa gejala. (Geni.L, 2016)

Batuk merupakan suatu mekanisme refleks yang sangat penting untuk menjaga jalan napas agar tetap terbuka dengan cara menyingkirkan hasil sekresi lendir yang menumpuk, gumpalan darah dan benda asing pada jalan napas, selain itu batuk juga dapat disebabkan oleh iritasi jalan napas. Batuk karena iritasi pada mukosa bronkus disebabkan oleh peradangan, baik oleh bakteri, virus, dan jamur disertai dengan mukus yang banyak. (Thristy.I, 2016)

Akhir-akhir ini perhatian terhadap penyakit mikosis paru semakin meningkat dan kejadian infeksi jamur paru semakin sering dilaporkan. Angka kekerapan mikosis paru di dunia dan di Indonesia belum diketahui secara pasti, hal ini akibat sulitnya mendiagnosis mikosis paru karena permasalahannya adalah gambaran klinis maupun radiologik penderita mikosis paru tidak khas. (Thristy.I, 2016)

Lansia merupakan salah satu kelompok atau populasi berisiko tentang masalah kesehatan atau rendahnya sistem imun sehingga kemungkinan dapat terinfeksi jamur dilingkungan sekitarnya. Lansia yang 
mengalami batuk kemungkinan bisa disebabkan karena jamur sehingga dapat dilakukan dengan pemeriksaan biakan jamur pada sputumnya, biasanya jamur yang sering ditemukan dalam pemeriksaan ini adalah jamur Aspergillus sp dan Candida sp. (Allender, 2014).

Panti jompo merupakan sebuah rumah atau tempat penampungan untuk manusia lanjut usia (manula). Lanjut usia adalah periode dimana organisme telah mencapai kematangan dalam ukuran, fungsi dan telah menunjukkan perubahan sejalan dengan waktu, Sehingga lansia sangat rentan terhadap penyakit, sebagian orang kurang menjaga kesehatan maupun perawatan pada tubuh. (Indriana, 2014).

Panti Sosial Tresna Werdha Budi Mulia 1 Cipayung mempunyai 7 wisma yang terdiri dari Wisma Asoka, Wisma Bougenville, Wisma Cempaka, Wisma Dahlia, Wisma Catellya, Wisma Edelwais dan Wisma Flamboyan. Lansia yang tinggal di Panti Sosial Tresna Werdha Budi Mulia 1 Cipayung yaitu 210 lansia, yang terdiri dari 120 nenek dan 90 kakek. Dari 7 wisma yang dihuni lansia tersebut masing-masing wisma terdapat lansia yang mengalami batuk, lansia berpotensi untuk terinfeksi jamur.(Isnaniyah, 2014)

Individu dengan sistem imun yang lemah juga mempunyai resiko mengalami infeksi jamur, misalnya penderita HIV/AIDS dan pengguna obat-obatan steroid. Penderita diabetes, anak kecil dan bayi serta orang lanjut usia juga beresiko mengalami infeksi jamur. (Indriana, 2014).

Kultur sputum standar memiliki hasil yang rendah dalam mendeteksi jamur. Secara konvensional hanya sebagian kecil dari spesimen yang dibiakkan. Oleh karena itu kinerja High Volume Culture (HVC) di mana seluruh spesimen dilapisi pada Sabouraud Dekstrose Agar (SDA). (Vergidis, P.,2017)

Penelitian ini menggunakan metode $\mathrm{HVC}$ dengan suhu $40^{\circ} \mathrm{C}$ dan suhu kamar dimana pada suhu $40^{\circ} \mathrm{C}$ untuk mendapatkan jamur Aspergillus fumigatus karena jamur ini tergolong jamur patogen oportunistik yang bisa menyebabkan infeksi pada manusia dengan sistem imun yang rendah, jamur Aspergillus memiliki suhu optimum untuk tumbuh dan berkembang pada rentang $\pm 30^{\circ} \mathrm{C}$, adapun jamur Candida yang tumbuh pada suhu $40^{\circ} \mathrm{C}$ yaitu jamur Candida albicans, namun pada suhu kamar dengan metode HVC untuk mengidentifikasi jamur Aspergillus sp dan Candida sp.(Lubis.RD, 2014) 
Hasil penelitian Vergidis (2017) yang berjudul Kultur sputum High Volume Culture (HVC) untuk Diagnosis Aspergillosis Paru dengan metode High Volume Culture (HVC) yang masing-masing ditanam di suhu $40^{\circ} \mathrm{C}$ dan suhu kamar, Aspergillus ditemukan di metode HVC. Spesies Aspergillus yang sama ditemukan pada metode HVC dan kultur konvensional pada 50 spesimen berpasangan. Untuk 142 spesimen tidak ada pertumbuhan Aspergillus oleh HVC. Untuk dua spesimen HVC negatif $A$. fumigatus tumbuh dengan kultur konvensional. Spesies berikut ditemukan oleh HVC: $A$. fumigatus (80\%), A. niger (10\%), A. flavus (3\%), lainnya (7\%). Pengujian kerentanan (standar EUCAST) dilakukan untuk 127 isolat A. fumigatus.

Berdasarkan latar belakang di atas penulis merasa perlu melakukan penelitian tentang jamur pada sputum lansia di Panti Sosial Tresna Werdha Budi Mulia 1 Cipayung Jakarta Timur dengan metode HVC pada suhu $40^{\circ} \mathrm{C}$ dan suhu kamar.

\section{METODE}

Tempat pengambilan sampel dilakukan di Panti Sosial Tresna Werdha Budi Mulia 1 Cipayung Jakarta Timur pada tanggal 6 sampai dengan 7 agustus 2019. Penelitian ini dilakukan di laboratorium Mikrobiologi jurusan Analis Kesehatan MH. Thamrin mulai dari tanggal 14 sampai dengan 16 agustus 2019. Populasi dari penelitian ini adalah lansia di Panti Sosial Tresna werdha Budi Mulia 1 Cipayung Jakarta Timur. Sampel pada penelitian adalah lansia di Panti Sosial Tresna werdha Budi Mulia 1 Cipayung Jakarta Timur yang mengalami batuk dan tidak batuk yang diperiksa jamur pada sputumnya berjumlah 63 orang namun pada saat pengambilan sampel hanya didapatkan 50 sampel sputum dari jumlah lansia yang keseluruhan populasinya adalah 210 orang yang tinggal di Panti Sosial Tresna werdha Budi Mulia 1 Cipayung Jakarta Tmur. SAMPEL YANG DIDAPAT DILAKUKAN PEMERIKSAAN BIAKAN PADA MEDIA SDA

\section{HASIL DAN PEMBAHASAN}


Pada bulan Agustus 2019 telah dilakukan pengambilan sampel di Panti Sosial Tresna Werdha Budi Mulia 1 Cipayung Jakarta Timur dengan sampel size 63 sampel sputum, namun pada saat pengambilan hanya didapatkan 50 sampel sputum dari 25 lansia yang mengalami batuk dan 25 lansia yang tidak mengalami batuk. Dari pemeriksaan biakan SDA 50 sampel dengan metode HVC yang diinkubasi pada suhu $40^{\circ} \mathrm{C}$ dan suhu ruang didapatkan hasil jamur Candida sp dan Aspergillus sp. (tabel 1)

\section{Tabel 1}

Hasil Biakan Jamur Candida sp dan Aspergillus sp Dari Seluruh 50 Sputum lansia Di Panti Sosial Tresna Werdha Budi Mulia 1 Cipayung Jakarta Timur Dengan Metode HVC Berdasarkan Jenis Kelamin

\begin{tabular}{lccc}
\hline \multirow{2}{*}{ Karakteristik } & \multicolumn{3}{c}{ Pertumbuhan jamur } \\
\cline { 2 - 4 } & Positif & Aspergillus sp dan Candida $\boldsymbol{s p}$ \\
\hline Laki-laki & $18(36 \%)$ & $4(8 \%)$ & Jumlah \\
\hline Perempuan & $28(56 \%)$ & $0(0 \%)$ & $22(44 \%)$ \\
\hline Jumlah & $46(92 \%)$ & $4(8 \%)$ & $50(100 \%)$ \\
\hline
\end{tabular}

(Sumber : Data primer, 2019)

Berdasarkan hasil dari tabel 1 diketahui jumlah jamur dari 50 sampel didapatkan jamur positif Candida $s p$ dan Aspergillus sp sebanyak 46 sampel dengan persentase (92\%) sedangkan yang negatif sebanyak 4 sampel dengan persentase (8\%). Pada 50 lansia yang diperiksa laki-laki sebanyak 22 orang dan perempuan 28 orang. Hasil pemeriksaan jamur pada sputum lansia laki-laki didapatkan 18 sampel positif jamur (36\%) dan pada lansia perempuan didapatkan hasil jamur yang positif pada biakan sputum sebanyak 28 dengan persentase (56\%). Lansia yang diperiksa 25 orang mengalami keluhan batuk dan 25 orang tidak mengalami keluhan batuk. Hasil pemeriksaan jamur berdasarkan keluhan dapat dilihat pada tabel 2.

Tabel 2

Hasil Biakan Jamur Candida sp dan Aspergillus sp Dari Seluruh 50 Sputum Lansia Di Panti Sosial Tresna Werdha Budi Mulia 1 Cipayung Jakarta Timur Dengan Metode HVC Berdasarkan Gejala Batuk

\begin{tabular}{lccc}
\hline \multirow{2}{*}{ Gejala Lansia } & \multicolumn{4}{l}{ Pertumbuhan Jamur Aspergillus sp dan Candida sp } \\
\cline { 2 - 4 } & \multicolumn{4}{c}{ Positif (+) } & Negatif (-) & Jumlah \\
\hline Batuk & $23(46 \%)$ & $2(4 \%)$ & $25(50 \%)$ \\
\hline Tidak Batuk & $23(46 \%)$ & $2(4 \%)$ & $25(50 \%)$ \\
\hline Jumlah & $46(92 \%)$ & $4(8 \%)$ & $50(100 \%)$ \\
\hline
\end{tabular}

(Sumber : Data primer, 2019) 
Berdasarkan hasil dari tabel 2 diketahui jumlah sampel yang positif jamur Candida $s p$ dan Aspergillus $s p$ baik dari lansia yang menderita batuk maupun yang tidak menderita batuk didapatkan 23 sampel dengan persentase (46\%) sedangkan sisanya tidak tumbuh jamur Candida sp dan Aspergillus sp.

Hasil identifikasi koloni jamur yang ditemukan didapatkan 3 jenis jamur Aspergillus yaitu Aspergillus niger, Aspergillus flavus, Aspergillus fumigatus dan didapatkan jamur Candida sp. Selain kedua jamur tersebut ditemukan jamur jenis lainnya (Mycelia sterilia, Sincephalastrum, Mucor, Penicilium, Geotricum, Rhizopus, Rhodotorula.) hasil identifikasi berdasarkan suhu inkubasi dapat dilihat pada tabel 3.

Tabel 3

Hasil Pemeriksaan Kepadatan Jamur Aspergillus sp dan Candida sp Pada Biakan Sputum Lansia Di Panti Sosial Tresna Werdha Budi Mulia 1 Cipayung Dengan Metode HVC Suhu $4^{\circ} \mathrm{C}$ dan Suhu Kamar

\begin{tabular}{lcc}
\hline \multirow{2}{*}{ Jenis Jamur } & \multicolumn{2}{c}{ Persentase } \\
\cline { 2 - 3 } & Suhu $\mathbf{4 0} \mathbf{C}$ & Suhu kamar \\
\hline Aspergillus niger & $2(5,7 \%)$ & $17(17,7 \%)$ \\
\hline Aspergillus flavus & $2(5,7 \%)$ & $26(27 \%)$ \\
\hline Aspergillus fumigatus & $6(17,1 \%)$ & $4(4,2 \%)$ \\
\hline Candida sp & $20(57,2 \%)$ & $34(35,5 \%)$ \\
\hline Jamur Lainnya & $5(14,3)$ & $15(15,6 \%)$ \\
\hline Jumlah & $35(100 \%)$ & $96(100 \%)$ \\
\hline
\end{tabular}

(Sumber : Data primer, 2019)

Berdasarkan hasil tabel 3 diketahui inkubasi pada suhu $40^{\circ} \mathrm{C}$ didapatkan 35 koloni dari hasil biakan 27 sampel sputum sedangkan inkubasi pada suhu kamar didapatkan 96 koloni jamur dari hasil biakan 46 sampel sputum. Jenis jamur yang didapatkan dari biakan sputum pada suhu $40^{\circ} \mathrm{C}$ yaitu jamur Aspergillus $s p$ sebanyak 10 dengan persentase (28,6\%) yang terdiri dari Aspergillus niger (5,7\%), Aspergillus flavus (5,7\%), Aspergillus fumigatus (17,1\%) dan jamur Aspergillus yang mendominasi adalah jamur Aspergillus fumigatus. Pada biakan suhu kamar didapatkan jamur Aspergillus sebanyak 47 dengan persentase (49\%) yang terdiri dari Aspergillus niger (17,7\%), Aspergillus flavus (27\%), Aspergillus fumigatus (4,2\%) dan 
jamur Aspergillus yang mendominasi adalah jamur Aspergillus flavus. Jamur Candida sp didapatkan pada suhu $40^{\circ} \mathrm{C}$ persentase positif lebih banyak yaitu 20 (57,2\%) dari pada suhu kamar yaitu 34 (35,5\%).

Tabel 4

Hasil Pemeriksaan Kepadatan Jamur Candida sp Pada Biakan Sputum Lansia Di Panti Sosial Tresna Werdha Budi Mulia 1 Cipayung Dengan Metode HVC Suhu $4^{\circ} \mathrm{C}$ dan Suhu Kamar

\begin{tabular}{|c|c|c|c|c|}
\hline \multirow{2}{*}{$\begin{array}{l}\text { Kepadatan Koloni } \\
\text { Candida } s p\end{array}$} & \multicolumn{4}{|c|}{ HVC } \\
\hline & Suhu $40^{\circ} \mathrm{C}$ & Persentase & Suhu Kamar & Persentase \\
\hline Positif $+<50$ & 12 & $60 \%$ & 17 & $50 \%$ \\
\hline Positif $++50-100$ & 8 & $40 \%$ & 17 & $50 \%$ \\
\hline Positif $+++>100$ & 0 & $0 \%$ & 0 & $0 \%$ \\
\hline Jumlah & 20 & $100 \%$ & 34 & $100 \%$ \\
\hline
\end{tabular}

(Sumber : Data primer, 2019)

Pada tabel 4 didapatkan kepadatan Candida sp positif-1 lebih banyak didapatkan pada suhu $40^{\circ} \mathrm{C}$ yaitu 12 (60\%) dibandingkan pada suhu kamar didapatkan 17 (50\%) sedangkan pada kepadatan Candida $s p$ positif-2 lebih banyak didapatkan pada inkubasi suhu kamar yaitu $17(50 \%)$ dari pada suhu $40^{\circ} \mathrm{C}$ yaitu 8 (40\%). Biakan sputum dengan metode $\mathrm{HVC}$ pada suhu $40^{\circ} \mathrm{C}$ ditujukan untuk mengetahui jamur patogen yang menginfeksi paru yaitu Aspergillus fumigatus dan hasil pemeriksaan dapat dilihat pada tabel 5.

Tabel 5

Hasil Biakan Jamur Aspergillus fumigatus Pada Sputum Lansia Yang Ditanam Pada Suhu $40^{\circ} \mathrm{C}$ Dengan Metode HVC

\begin{tabular}{lcc}
\hline \multirow{2}{*}{ Keterangan } & \multicolumn{3}{c}{ HVC } \\
\cline { 2 - 4 } & Positif (+) & Negatif (-) \\
\hline Batuk & $2(8 \%)$ & $23(92 \%)$ \\
\hline Tidak Batuk & $4(16 \%)$ & $21(84 \%)$ \\
\hline Jumlah & & 50 \\
\hline
\end{tabular}

(Sumber : Data primer, 2019)

Berdasarkan tabel 5 diketahui hasil pemeriksaan biakan SDA dengan metode $\mathrm{HVC}$ suhu $40^{\circ} \mathrm{C}$ pada lansia yang mengalami batuk didapatkan jamur Aspergillus fumigatus yang positif sebanyak 2 dengan persentase (8\%), jamur Aspergillus fumigatus yang negatif sebanyak 23 dengan persentase (92\%) sedangkan pada suhu kamar lansia yang tidak mengalami batuk didapatkan jamur Aspergillus fumigatus yang positif 
sebanyak 4 dengan persentase (16\%), jamur Aspergillus fumigatus yang negatif sebanyak 21 dengan persentase $(84 \%)$

Dari hasil biakan SDA yang telah dilakukan pada pemeriksaan 50 sampel dari 25 lansia yang mengalami batuk dan 25 lansia yang tidak mengalami batuk di Panti Sosial Tresna Werdha Budi Mulia 1 Cipayung Jakarta Timur. Berdasarkan dari pemeriksaan biakan SDA 50 sampel sputum lansia tersebut didapatkan jamur Candida sp dan Aspergillus sp yang artinya lansia di Panti Sosial Tresna Werdha Budi Mulia 1 Cipayung Jakarta Timur kemungkinan terinfeksi jamur.

Berdasarkan hasil tabel 1 pada biakan dari 50 sampel sputum lansia di Panti Sosial Tresna Werdha Budi Mulia 1 Cipayung Jakarta Timur didapatkan hasil dari lansia perempuan 28 (56\%) lebih banyak dibandingkan dengan lansia laki-laki 18 (36\%) dikarenakan pada penempatan wisma laki-laki dan perempuan dipisah, untuk wisma yang ditempati pada wisma lansia perempuan terdapat 5 wisma yaitu Wisma Asoka, Wisma Cempaka, Wisma Dahlia,Wisma Bougenville dan Wisma Catelya yang masingmasing wisma ditempati pada lansia kurang lebih 30 lansia dan pada lansia laki-laki yaitu ada 2 wisma yang terdiri dari Wisma Flamboyan dan Wisma Edelweis dan dalam 1 wisma ditempati lansia laki-laki kurang lebih 40 lansia.

Berdasarkan hasil tabel 2 pada lansia yang mengalami batuk dan tidak mengalami batuk didapatkan hasil yang sama yaitu $23(46 \%)$ yang artinya berkemungkinan besar lansia yang tidak mengalmai batuk terinfeksi jamur Candida $s p$ dan Aspergillus sp yang memang untuk penyebaran spora jamur Aspergillus sangat banyak di udara sekitar bila lansia dalam kondisi imun yang rendah menghirup spora jamur Aspergillus maka spora tersebut akan masuk kedalam paru-paru dan berkembang biak di dalam paru-paru karna jamur Aspergillus dapat berkembang biak secara optimum pada suhu $\pm 30^{\circ} \mathrm{C}$ dan untuk jamur Candida $s p$ dalam kondisi normal ditemukan di tubuh manusia tetapi jika lansia dengan sistem imun yang rendah berkemungkinan jamur Candida sp bisa bersifat patogen bagi tubuh lansia tersebut sehingga dapat menginfeksi.Berdasarkan hasil tabel 3 dari pemeriksaan kepadatan jamur Aspergillus sp dan Candida $s p$ pada biakan sputum lansia di Panti Sosial Tresna Werdha Budi Mulia 1 Cipayung Jakarta Timur metode 
HVC dengan suhu $40^{\circ} \mathrm{C}$ didapatkan jamur Aspergillus yang mendominasi yaitu jamur Aspergillus fumigatus $6(17,2 \%)$ karena pada suhu $40^{\circ} \mathrm{C}$ target penelitian ini adalah untuk mendapatkan jamur Aspergillus fumigatus namun dalam suhu ini jamur Aspergillus Niger, Aspergillus Flavus, Candida sp dan jamur lainnya pun tumbuh, jamur Candida sp yang tumbuh pada suhu $40^{\circ} \mathrm{C}$ juga cukup tinggi yaitu 20 $(57,2 \%)$ yang berkemungkinan jamur yang tumbuh adalah jamur Candida albicans karena jamur ini bersifat patogen dan dapat tumbuh pada suhu $40^{\circ} \mathrm{C}$. Jamur Aspergillus niger, Aspergillus flavus dan beberapa jenis jamur lainnya yang tumbuh pada suhu $40^{\circ} \mathrm{C}$ didapatkan karena kesalahan pada peneliti karena saat di identifikasi jamur pada cawan petri yang dari inkubator suhu $40^{\circ} \mathrm{C}$ dikeluarkan semua dan penempatannya di sejajarkan di meja laboratorium dengan cawan petri yang diinkubasi pada suhu kamar sehingga berkemungkinan jamur yang tumbuh selain jamur Aspergillus fumigatus dan jamur Candida albicans merupakan kontaminasi dari udara dan cawan petri yang sudah ditumbuhi jamur tersebut. Pada suhu kamar dalam biakan sputum lansia hampir merata ditumbuhi jamur Candida sp, Aspergillus niger, Aspergillus flavus, Aspergillus fumigatus dan beberapa jenis jamur lainnya karena dalam suhu ini jamur dapat tumbuh secara optimum. Jamur Aspergillus niger dapat tumbuh secara optimum pada suhu $35-37^{\circ} \mathrm{C}$. Fungi diketahui lebih tahan dalam keadaan lingkungan yang tidak menguntungkan dari pada mikroorganisme lain, fungi umumnya menghendaki oksigen sehingga bersifat aerob sejati, tetapi khamir (yeast) bersifat kualitatif yang atinya dapat hidup dalam keadaan aerob maupun anerob, suhu optimum pertumbuhan fungi parasit lebih tinggi yaitu $30-37^{\circ} \mathrm{C}$ dari pada jenis yang saprofit hidup pada suhu 22 $30^{\circ} \mathrm{C}$. (pelczar dkk, 1986)

Berdasarkan hasil tabel 4 Candida sp merupakan jenis jamur yang dalam keadaan normal dapat ditemukan pada tubuh seseorang dalam jumlah kecil namun pada keadaan tubuh yang lemah atau imun yang rendah jamur ini dapat bersifat patogen, jamur Candida dapat tumbuh di suhu $40^{\circ} \mathrm{C}$ yaitu jamur Candida albicans. Kepadatan Candida yang ditemukan pada biakan sputum lansia baik pada suhu $40^{\circ} \mathrm{C}$ maupun suhu kamar kisaran positif-1 dan positif-2. Kepadatan Candida pada sputum tidak menunjukan patogenitas sebagai penyebab penyebab kandidiosis paru karena harus ditunjang dengan pemeriksaan 
lainnya untuk memastikan diagnosis sebagai kandidiosis paru. Candida hanya sebagai kolonisasi setempat saja terutama kolonisasi dirongga mulut karena sputum yang didapatkan melewati rongga mulut.

Berdasarkan hasil tabel 5 diketahui pada biakan jamur sputum lansia dengan metode $\mathrm{HVC}$ pada suhu $40^{\circ} \mathrm{C}$ didapatkan jamur patogen oportunistik yaitu jamur Aspergillus fumigatus pada lansia yang mengalami batuk dan tidak mengalami batuk namun pada lansia yang tidak mengalami batuk didapatkan jamur Aspergillus fumigatus lebih banyak dibandingkan dengan lansia yang mengalami batuk, jamur ini dapat tumbuh pada pada lansia yang tidak mengalami batuk mungkin karena faktor lain seperti penyakit DM, Asma, Alergi dan TB yang berkemungkinan besar lansia dengan sistem imun yang rendah dapat terinfeksi oleh jamur Aspergillus fumigatus.

Aspergillosis didefinisikan sebagai suatu kelompok mikosis dari berbagai macam jamur patogen genus Aspergilllus sp. Spora Aspergillus sp tersebar bebas di udara terbuka sehingga inhalasinya tidak dapat dihindarkan dan masuk melalui saluran pernapasan ke dalam paru. Aspergillus tumbuh dan berkembang pada suhu optimum yaitu pada suhu $\pm 30^{\circ} \mathrm{C}$ yang hampir sama pada suhu tubuh manusia yaitu $36,5-$ $37,2^{\circ} \mathrm{C}$, oleh sebab itu pada penanaman disuhu kamar, Aspergillus sp tumbuh merata walaupun tidak sebanyak Candida sp.

Penelitian ini menggunakan metode $\mathrm{HVC}$ dengan suhu $40^{\circ} \mathrm{C}$ untuk mendapatkan jenis jamur Aspergillus fumigatus yang bersifat patogen dan tergolong jamur oportunistik dan pada suhu ini juga jamur Candida albicans dapat tumbuh. Pada suhu kamar didapatkan jenis jamur Candida sp dan jamur Aspergillus niger, Aspergillus flavus, Aspergillus fumigatus dan jenis jamur lainnya.

Hasil penelitian ini sama dengan penelitian Vergidis, P.,2017 dengan judul "Kultur sputum HVC untuk Diagnosis Aspergillosis Paru” dengan hasil yang ditemukan Aspergillus sp dan Candida sp dimana faktor imunitas lansia yang rendah juga memungkinkan terjadinya Aspergillosis dan Candidiasis pada paru.

\section{SIMPULAN}

Diketahui pada biakan sputum lansia lebih banyak didapatkan jamur Candida $s p$ dan Aspergillus $s p$ pada lansia perempun dibandingkan dengan lansia laki-laki, Diketahui kepadatan jamur Candida sp positif-1 
lebih banyak didapatkan pada suhu $40^{\circ} \mathrm{C}(60 \%)$ dibandingkan pada suhu kamar yaitu $17(50 \%)$ sedangkan pada kepadatan Candida sp positif-2 lebih banyak didapatkan pada suhu kamar yaitu 17 (50\%) dibandingkan dengan suhu $40^{\circ} \mathrm{C} 8$ (40\%). Diketahui jamur Aspergillus fumigatus pada suhu $40^{\circ} \mathrm{C}$ lebih banyak didapatrkan pada lansia yang tiak mengalami batuk dibandingkan dengan lansia yang mengalami batuk.

\section{UCAPAN TERIMA KASIH}

Penulis mengucapkan terima kasih kepada Panti Sosial Tresna werdha Budi Mulia 1 Cipayung Jakarta Timur dan Prodi D III Analis Kesehatan Universitas MH Thamrin berperan serta dalam penelitian ini.

\section{DAFTAR PUSTAKA}

1. Allender, J.A., Rector, C., \& Warner, K.D. (2014). Community dan public health nursing promoting the public's health (8th Ed.) Philadelphia: Lippincott Williams \& Wilkins

2. Anonim. 2013. Pencegahan Aspergillosis di Hatchery dengan Clinafarm. http://www.novindo.co.id/index.php?option=com_content\&view $=$ article \&id=41:aspergillusprevention-in-hatchery-with-clinafarmr\&catid=2:articles\&Itemid $=3$

3. Bennet W. J, 2010, An Overview of the Genus Aspergillus, di dalam: Aspergillus Molecular and Genomics, Edited by Masayuki Machida and Katsuya Gomi, Japan, pp 1-17

4. Ellis.D,2015.Aspergillusflavus.http://www.mycology.adelaide.edu.au./Fungal_Descriptions/Hyphom ycetes_(hyaline)/Aspergillus/flavus.html. Diakses pada Tanggal 9 Agustus 2015 (13.57)

5. Gandahusada S, Ilahude H, Harry D dan Pribadi W. 2004. Parasitologi kedokteran. FKUI:Jakarta.

6. Geni.L, Zuraida, Violita.V,. Ilmu Kesehatan, 8(1); Januari 2016., Hitung Jumlah Koloni Jamur Dan Identifikasi Jamur Pada Sputum Penderita Tuberkulosis Paru Dari Rumah Sakit X Dan Y Di Jakarta

7. Hasanah.U , Keluarga Sehat Sejahtera Vol. 15 (30) Desember 2017., Mengenal Aspergillosis, Infeksi Jamur Genus Aspergillus

8. Hidayatullah,T., 2018 Identifikasi Jamur Rhizopus Sp Dan Aspergillus Sp Pada Roti Bakar Sebelum Dan Sesudah Dibakar Yang Dijual Di Alun-Alun Jombang

9. Indriana, dkk., 2014., Tingkat Stres di Panti Wredha Pucang Gading Semarang. Jurnal Psikologi Universitas Diponegoro. Semarang UniversitasDiponegoro.http://ejournal.undip.ac.id/index.php/psikologi/article/view/29 53/2639.

10. Isnaniya., 2014., Implementasi Program Dinamika Kelompok Terhadap Lanjut Usia Di Panti Sosial Tresna Werdha Budi Mulia 1 Cipayung Jakarta Timur

11. Kemenkes RI. Profil Kesehatan Indonesia tahun 2014. Jakarta : Kemenkes RI; 2015.

12. Konsesus FKUI-PMKI, 2001, Tatalaksana Mikosis Sistemik, Perhimpunan Mikologi Kedokteran Manusia dan Hewan Indonesia, Fakultas Kedokteran Universitas Indonesia

13. Lubis.RD s, 2014. Aspergillosis

14. Misnadiarly, 2009, Penyakit Infeksi Saluran Napas Pneumoni pada Anak Orang Dewasa, Usia Lanjut Edisi 1, Jakarta, Pustaka Obor Populer.

15. Pelczar, Michael J dan Chan, E. C. S. 2009. Dasar-Dasar Mikrobiologi Jilid I. Jakarta: UI Press.

16. Thristy.I, Siregar.Y, MKB. 2016;48(2):78-83 Aspergillus fumigatus pada Sputum Penderita Batuk Kronik Menggunakan Metode PCR dan Kultur

Open Journal System (OJS): journal.thamrin.ac.id

http://journal.thamrin.ac.id/index.php/anakes/issue/view/35 
17. Vergidis, P., Moore, C., Rautemaa-Richardson, R., \& Richardson, M. (2017). High-volume Sputum Culture for the Diagnosis of Pulmonary Aspergillosis. Open Forum Infectious Diseases, 4(Suppl 1), S609. doi:10.1093/ofid/ofx163.1598

18. http://www.klikparu. com/2013/02/ jamur-paru.html

19. http://ariakiki.blogspot.com/2016/05/makalah-sputum.html?m=1

20. http://dyanelekkodhog.blogspot.com/2014/10/candida-sp.html?=1

21. http://muhlisin.A.honestdocs.id/2019/07/candidiasis 